\title{
Response of Intractable Post Herpetic Neuralgia to INTRATHECAL BACLOFEN
}

\author{
Amr Hosny, MD, Thomas Simopoulos, MD, and Beth Collins, RN \\ An intractable case of Post-herpetic \\ Neuralgia (PHN) in which all other treat- \\ ment options were exhausted was suc- \\ cessfully treated with intrathecal baclofen \\ infusion with a complex continuous deliv- \\ ery mode. \\ A 72-year old man presented to the \\ pain clinic with a 4-year history of left lower \\ extremity PHN. He had seen multiple experts \\ in the field, failed numerous pharmacological \\ therapies, and interventional techniques. Af- \\ ter multiple neuraxial medications were tried, \\ baclofen was chosen and an intrathecal drug \\ delivery system was implanted. Eight months \\ after the procedure he continues to have 80 \\ $\%$ pain relief.
}

PHN is a devastating complication of shingles. Fortunately, most cases respond to conventional therapies. For intractable cases intrathecal baclofen appears to be a safe and effective therapeutic modality.

Keywords: Post herpetic neuralgia, intrathecal baclofen, complex continuous delivery mode
Intrathecal baclofen (Lioresal Intrathecal, Medtronic Neurological, Minneapolis, MN) is a Food and Drug Administration (FDA)-approved therapy for medically intractable spasticity. The importance of gamma-aminobutyric acid (GABA) as an inhibitory neurotransmitter modulating either spasticity or persistent neuropathic pain states is without debate $(1,2)$. Animal data strongly supports the analgesic properties of intrathecal GABA agonists such as baclofen (3). Indeed there are a growing number of reports of intrathecal baclofen successfully used to manage chronic pain without spasticity $(4,5)$. In these reports, intrathecal baclofen did not produce intolerable side effects such as sedation or motor dysfunction (6). Here we present a case of refractory post-herpetic neuralgia $(\mathrm{PHN})$ responding to intrathecal baclofen.

\section{Case Report}

A 72 year-old male presented to our pain management center in 2001 with a 4 year history of left lower extremity pain secondary to PHN. This pain started 15

From Beth Israel Deaconess Medical Center, Harvard Medical School, Boston, MA. Address Correspondence: Amr Hosny, MD, St. Vincent's Hospital, 170 West 12th St. NR 408, New York, NY 10011 E-mail: ahosny@svemcny.org

Support: No financial support for this case report was received.

Conflict of Interest: None

Acknowledgement: Manuscript received on 3/6/04. Revision submitted on 4/4/04. Accepted for publication on 4/4/04.. days after the development of acute herpes zoster in the context of a steroid treatment for Grave's disease in 1997. His past medical history is significant only for one episode of atrial fibrillation. Despite initial acyclovir treatment, the pain had gradually worsened over the years. He described his pain as constant burning and throbbing with periods of sharp lancinations (as frequent as every 3 seconds) in the thigh that was exacerbated by walking or light contact with loose fitting pants. He reported improvement of pain when constant firm pressure was applied to his thigh. His pain would escalate with activity, and therefore significantly impacted his ambulation, thereby limiting his activities of daily living.

The physical examination revealed a healthy, well built but uncomfortable appearing elderly male. He was applying constant pressure to his left thigh. The sensory examination was without deficit to pin prick, and his reflexes were symmetrical (1 /2) in the lower extremities. Motor examination was 5/5 in all major muscle groups in the lower extremities. He had marked hyperalgesia, hyperpathia and allodynia, most notable in the L3 distribution of the left lower extremity. The right lower extremity was unremarkable. There were healed zoster scars in the left L3 dermatome.

On presentation to the pain clinic he was on gabapentin $600 \mathrm{mg}$ po tid, Synthroid, baclofen $20 \mathrm{mg}$ po bid, low dose aspirin, multivitamins and zolpidem as a sleep aid. He reported some benefit from the gabapentin and baclofen at the current doses, but complained of side effects with increased dosage. His visual analog score (VAS) ranged from 7/10- 10/10. Multiple narcotics, tricyclic antidepressants, anti-convulsants, topical agents, and anti-arrhythmic drugs were tried without benefit. He had also tried a TENS unit, selective nerve root blocks, lumbar sympathetic blocks, lumbar epidural steroids, and spinal cord stimulation, again without benefit.

Under our care, he received a series of 4 intrathecal steroid injections on a weekly basis with limited short-lived pain relief. After a lengthy discussion with the patient we decided to try neuraxial agents. An intrathecal catheter was inserted (L4/5) and he was admitted to the hospital for 5 days. Injection of intrathecal morphine $(0.5 \mathrm{mg})$, hydromorphone $(0.2 \mathrm{mg})$, as well as clonidine $(30 \mathrm{mcg})$ on separate days, provided $30 \%$ pain relief, but they were associated with significant sedation and/or urinary retention. A trial of intrathecal baclofen as a $50 \mathrm{mcg}$ bolus provided marked pain relief but again was associated with sedation. On the fifth day, just prior to removal of the catheter, a $25 \mathrm{mcg}$ bolus of baclofen was injected intrathecally with significant pain relief without sedation lasting 8 hours. Several weeks later, a $25 \mathrm{mcg}$ subarachnoid injection of baclofen rendered similar effects on the pain level (VAS reduced by greater than 50\%). The decision was made to implant an intrathecal drug delivery system.

A programmable pump (Medtron- 
ic SyncroMed ${ }^{\mathrm{TM}}$; Medtronic Neurological Inc, Minneapolis, MN) was implanted uneventfully. The catheter was introduced at L4-5 and advanced under fluoroscopic guidance to the T12 level. The pump was filled with baclofen $500 \mathrm{mcg}$ per $\mathrm{mL}$ (a total of $18 \mathrm{~mL}$ ) and was programmed to deliver $75 \mathrm{mcg}$ per day as a simple continuous infusion. He reported no alleviation of his pain the next day. A $25 \mathrm{mcg}$ bolus (via the pump) was given and the patient reported good pain relief for about 8 hours. We then increased the flow to 100 mcg per day as a simple continuous infusion. The next day he complained of leg pain (VAS 7/10). A forty mcg bolus was given and again he reported excellent pain relief for 8 hours (VAS 1/10). Further increases in the simple continuous mode resulted in sedation and no improvement in pain control.

After the realization that analgesia came about only with bolus dosing, it was decided to change the mode of delivery to complex continuous with three daily boluses (40 mcg) while keeping the background infusion at $70 \mathrm{mcg}$ per day. The first was at $5 \mathrm{am}$, the second at $11 \mathrm{am}$ and the third at $5 \mathrm{pm}$, with a total daily dose of $189.53 \mathrm{mcg}$ per day (Fig. 1). The background infusion provided excellent pain relief through the night.

Subsequent to obtaining the proper complex continuous delivery program, the patient experienced elimination of his stabbing pain as well as throbbing and burning sensations. He reports marked improvement in ambulation, sleep, and work related activities. He also went on vacation abroad 7 months after pump implantation. There was fair reduction in allodynia to the point where he could shower but light touch was still unpleasant. He remains comfortable (VAS $=0-4 / 10$ ) nearly one-year post implantation.

\section{DISCUSSION}

Intrathecal baclofen has remained efficacious in our PHN patient without further dose adjustment. A modality that allows for bolus delivery seems to be necessary for intrathecal baclofen to render effective analgesia. A pulsatile release may more closely mimic physiologic release of inhibitory amino acids. Our rationale for introducing intrathecal baclofen during the trial phase was based on previous animal data, prior human experience in neuropathic pain states, and failure to respond to spinal cord stimulation (SCS).
Spinal GABA release during SCS is one important neurochemical mechanism by which hyperexcitability is reduced in the dorsal horn of experimental animals (7). We hypothesized a lack of GABA due to inhibitory interneuron destruction during the initial zoster attack.

In fact, atrophy of the dorsal horn is known to occur in patients with longterm PHN (8). Many neurons in the spinal cord contain inhibitory neurotransmitters such as GABA (9). In animal studies, peripheral damage to primary afferent neurons results in transsynaptic signs of degeneration of deafferentiated spinal neurons in the dorsal horn (10). Cells that have undergone these changes are termed "dark neurons" (11). If loss of inhibitory interneurons occurs in PHN, then spontaneous activity of a disinhibited dorsal horn can cause pain. Support for this theory comes from animal nerve injury models, which are associated with coexisting spinal interneuron disruption, where it has been observed that baclofen reduces pain behaviors and allodynia (12). But it is unknown what types of neurons or neurotransmitters are lost in PHN patients. Suffice it to say that in many patients suffering from PHN, peripheral as well as central nervous system changes are thought to play a role in the persistence of pain.

Intrathecal baclofen has been reported effective in other refractory neuropathic pain states including complex regional pain syndrome, radicular pain, stump pain, and sciatic nerve injury $(4,6$, 13). The authors of these cases observed a reduction in continuous and evoked pain as seen in our patient. The proposed molecular mechanisms of spinal baclofen are thought to be exerted both pre- and post synaptically in the dorsal horn via the $\mathrm{GABA}_{\mathrm{B}}$ receptor. There is inhibition of the release of excitatory amino acids presynaptically, while postsynaptically, activation of the $\mathrm{GABA}_{\mathrm{B}}$ receptor is linked to G-protein-mediated potassium channel activation (14). Potassium outflow from dorsal horn cells leads to hyperpolarization. These cellular mechanisms are thought to be the explanation for the reduction of both phase 1 and 2 pain behaviors of the formalin test in rats after the administration of intrathecal baclofen (15). Hwang and Yaksh (16) demonstrated that intrathecal baclofen moderates the effects of neuropathic pain generated by ligation of the L5/L6 nerve roots in rats (Chung model). They demonstrated that intrathecal baclofen reduces post nerve injury allodynia in rats without any apparent effect on motor function.

\section{Conclusion}

This case report lends more support to the observation that intrathecal baclofen is effective in some chronic neuropathic pain states that lack symptoms of spasticity. Our patient had failed multiple treatments and had suffered the torment of zoster related pain for many years. Intrathecal baclofen has been well established as safe and is FDA approved for intraspinal use but for spasticity only. Unlike morphine, which is FDA approved for intrathecal use for pain, baclofen is not associated with inflammatory catheter tip masses $(17,18)$. However abrupt intrathecal baclofen withdrawal can lead to life threatening sequelae and therefore the need for close long-term follow-up.

\section{Author Affiliation \\ Amr Hosny, MD \\ St. Vincent's Hospital \\ 170 West 12th St. NR 408 \\ New York, NY 10011 \\ Email: ahosny@svcmcny.org \\ Thomas Simopoulos, MD \\ Beth Israel Deaconess Medical Center \\ Harvard Medical School \\ 330 Brookline Avenue \\ Boston, MA 02215 \\ Beth Collins, RN \\ Beth Israel Deaconess Medical Center Harvard Medical School \\ 330 Brookline Avenue \\ Boston, MA 02215}

\section{REFERENCES}

1. Butler C, Campbell S. Evidence of the effects of intrathecal baclofen for spastic and dystonic cerebral palsy. AACPDM Treatment Outcomes Committee Review Panel. Dev Med Child Neurol 2000; 11:634-645.

2. Hammond DL, JJ Bonica - Lecture-2001: Role of spinal GABA in acute and persistent nociception. Reg Anesth Pain Med 2001; 26:551-557.

3. Sharma R, Mathur R, Nayar U. GABA B mediated analgesia in tonic pain in monkeys. Indian I Physiol Pharmacol 1993; 37:189193.

4. van Hilten BJ, van de Beek WJT, Hoff JI et al. Intrathecal baclofen for the treatment of dystonia in patients with reflex sympathetic dystrophy. N Engl J Med 2000; 343: 
625-630.

5. Vatine JJ, Magora F, Shochina $M$ et al. Effect of intrathecal baclofen in low back pain with root compression syndromes. Pain Clin 1989; 2:207-217.

6. Zuniga RE, Schlicht CR, Abram SE. Intrathecal baclofen is analgesic in patients with chronic pain. Anesthesiology 2000; 92:876-880.

7. Oakley JC, Prager JP. Spinal cord stimulation; Mechanisms of action. Spine 2002; 27:2574-2583.

8. Watson CP, Morshead C, Van der Kooy D et al. Post-herpetic neuralgia: Post-mortem analysis of a case. Pain 1988; 34:129-138.

9. Hunt SP, Kelly JS, Emrson PC et al. An immunohistochemical study of neuronal populations containing neuropeptides or gamma-aminobutyrate within the superficial layers of the rat dorsal horn. Neurosci- ence $1981 ; 6: 1883-1898$.

10. Sugimoto T, Bennett GJ, Kajander KC. Transsynaptic degeneration in the superficial dorsal horn after sciatic nerve injury: Effects of a chronic constriction injury, transection and strychnine. Pain 1990; 42:205-213.

11. Kajander KC, Bennett GJ. Onset of a painful peripheral neuropathy in rat: A partial and differential deafferentation and spontaneous discharge in A-gamma and A-gamma primary afferent neurons. I Neurophysiol 1992; 68:734-744.

12. Hwang JH, Yaksh TL. The effect of GABA receptor agonists on tactile allodynia in a surgically-induced neuropathic pain model in the rat. Pain 1997; 70:15-22.

13. Zuniga RE, Perera S, Abram SE. Intrathecal Baclofen: A useful agent in the treatment of wellestablished complex regional pain syndrome. Reg Anesth Pain Med 2002; 27:90-93.
14. Sawynok J. GABAergic mechanisms of analgesia: An update. Pharma Biochem Behav 1987; 26:463-474.

15. Dirig DM, Yaksh TL. Intrathecal baclofen and muscimol, but not midazolam, are antinociceptive using the rat formalin model. J Pharmacol Exp Ther 1995; 275:219-227.

16. Hwang JH, Yaksh TL. The effect of GABA receptor agonists on tactile allodynia in a surgically induced neuropathic pain model in the rat. Pain 1997; 70:15-24.

17. Yaksh TL, Hassenbusch S, Burchiel K et al. Inflammatory masses associated with intrathecal drug infusion: $A$ review of the preclinical evidence and human data. Pain Med 2002; 3:300-312.

18. Hassenbusch S, Burchiel K, Coffey RJ et al. Management of intrathecal catheter-tip inflammatory masses: A consensus statement. Pain Med 2002; 3:313-323. 
